\title{
Complete Genome Sequence Resource of a Strain of Curtobacterium flaccumfaciens pv. flaccumfaciens, the Causal Agent of Bacterial Wilt of Common Bean, from Turkey
}

Michael L. O'Leary and Robert L. Gilbertson

Department of Plant Pathology, University of California, Davis, One Shields Ave., Davis, CA 95616

\begin{abstract}
Curtobacterium flaccumfaciens pv. flaccumfaciens is the causal agent of bacterial wilt of common bean (Phaseolus vulgaris), a disease that can reduce yields of this economically important crop worldwide. Current genomics resources for this bacterial pathogen are limited. Therefore, long-read sequencing was used to determine the complete genome sequence of a pathogenic $C$. flaccumfaciens pv. flaccumfaciens strain isolated from common bean leaves showing irregular necrotic lesions with yellow borders collected in a commercial field in Turkey in 2015.
\end{abstract}

\section{Genome Announcement}

Curtobacterium flaccumfaciens pv. flaccumfaciens is a Gram-positive coryneform bacterium that causes bacterial wilt disease of common bean (Phaseolus vulgaris). Some C. flaccumfaciens pv. flaccumfaciens strains also cause bacterial wilt of other legume crops, including cowpea (Vigna unguiculata), soybean (Glycine max), and pea (Pisum sativum) (EPPO 2011; Osdaghi et al. 2015; Soares et al. 2013). Symptoms of bacterial wilt disease include wilting, leaf scorch and, less typically, necrotic lesions with yellow borders that closely resemble those of common bacterial blight, caused by Xanthomonas phaseoli and $X$. citri pv. fuscans (Zaumeyer and Thomas 1957). C. flaccumfaciens pv. flaccumfaciens is seed-transmissible, and infected seed may be shriveled or discolored.

Bacterial wilt was first described in South Dakota in the 1920s (Hedges 1922), and caused economic losses to common bean production in the Midwestern United States. By the 1970s, the disease was effectively managed through practices such as planting pathogen-free seeds, crop rotation, and sanitation (Harveson et al. 2015). However, in the early 2000s, bacterial wilt reemerged as an economically important disease in the United States, e.g., in the states of Colorado, Nebraska, and Wyoming (Harveson et al. 2006). The disease has also been reported from other countries including Australia, Brazil, Canada, Germany, Iran, Mexico, South Africa, Spain, and Turkey (EPPO 2011; Harveson et al. 2015; Osdaghi et al. 2015).

In 2015, a survey of bacterial diseases of common bean was conducted in Turkey. The predominant disease observed was common bacterial blight based on (i) observation of blighted

Current address for M. L. O'Leary: U.S. Department of Agriculture-Agricultural Research Service, San Joaquin Valley Agricultural Sciences Center, 9611 S. Riverbend Ave., Parlier, CA 93648.

Mention of trade names or commercial products in this publication is solely for the purpose of providing specific information and does not imply recommendation or endorsement by the U.S. Department of Agriculture. USDA is an equal opportunity provider and employer.

The author(s) declare no conflict of interest.

Accepted for publication 27 June 2020.

\section{Funding}

Support for this project came from a Henry A. Jastro Graduate Research Award provided by the College of Agricultural and Environmental Sciences of the University of California, Davis and from the May Seed Company.

\section{Keywords}

bacterial diseases, bacteriology,

Curtobacterium flaccumfaciens,

Phaseolus vulgaris, plasmid 
leaves having irregular lesions with water-soaked spots and lemon-colored borders, and (ii) consistent isolation of $X$. phaseoli on 523 medium, a general medium for isolation of Gramnegative and -positive plant pathogenic bacteria (Kado and Heskett 1970), and MXP, a semiselective medium for xanthomonads (Claflin et al. 1987). However, isolations from 5 of 18 such leaf samples, collected from three fields in the Burdur province, consistently yielded yellow mucoid colonies on 523 but not on MXP. A representative strain from a single colony of these yellow bacteria from each of these five samples was subcultured, and all were Gram-positive based on the $\mathrm{KOH}$ reaction (Suslow et al. 1982). Sequence analysis of the PCR-amplified ribosomal 16S-23S internal transcribed spacer region (Jensen et al. 1993) of the five strains revealed $>90 \%$ identity with sequences of strains of $C$. flaccumfaciens, including pathovars betae, flaccumfaciens, poinsettiae, and oortii. Furthermore, the expected-size $~ 300-b p$ fragment was amplified from total genomic DNA of these five strains by PCR with the C. flaccumfaciens pv. flaccumfaciens-specific primer pair CffFOR2 and CffREV4 (Tegli et al. 2002). Pathogenicity of these strains was assessed by inoculating the common bean cultivars Topcrop, Elinda, and Volare by stem-stabbing with $20 \mu \mathrm{l}$ of bacterial suspensions of approximately $10^{8} \mathrm{cfu} / \mathrm{ml}$ (EPPO 2011). Plants were maintained in a temperature-controlled greenhouse. By 21 days postinoculation, all five strains induced wilting and interveinal necrotic lesions with yellow borders on trifoliolate leaves. Together, these results indicated that these are strains belonging to $C$. flaccumfaciens pv. flaccumfaciens and are designated $\mathrm{Cff} 1035$ to Cff1039. Furthermore, these results demonstrated that some of the necrotic lesions with yellow borders observed on common bean leaves in the three fields in Burdur were symptoms of bacterial wilt caused by $C$. flaccumfaciens pv. flaccumfaciens rather than common bacterial blight caused by $X$. phaseoli or $X$. citri pv. fuscans.

Genetic typing studies (e.g., repetitive element sequence-based PCR, amplified fragment length polymorphism) of $C$. flaccumfaciens pv. flaccumfaciens strains have shown a large degree of heterogeneity (Agarkova et al. 2012; Gonçalves et al. 2019), but genomic resources necessary for further investigation of the genetic diversity among $C$. flaccumfaciens pv. flaccumfaciens strains are limited. Genome assemblies for two C. flaccumfaciens pv. flaccumfaciens strains known to be pathogenic on common bean are publicly available: a draft genome of the type strain (CFBP3418), which was isolated from common bean in Hungary in 1957, and a recently released complete genome sequence of a strain (P990) isolated from bell pepper (Capsicum sp.) in Iran in 2015 (Table 1). Four additional draft genomes of $C$. flaccumfaciens strains are also available, but most of these came from environmental samples, and it is not known if these strains are pathogenic on plants.

Therefore, the complete genome sequence of one of the pathogenic $C$. flaccumfaciens $\mathrm{pv}$. flaccumfaciens strains from Burdur, Turkey, Cff1037, was determined. A Cff1037 culture was grown in $50 \mathrm{ml}$ of liquid $2 \times$ yeast tryptone medium in a 250-ml Erlenmeyer flask overnight at $28^{\circ} \mathrm{C}$ on a rotary shaker at $150 \mathrm{rpm}$. Cells were recovered by centrifugation and total genomic DNA was extracted with a CTAB method (Koike et al. 1999). This DNA was used to prepare a 15-kb BluePippin size-selected sequencing library by the UC Davis Genome Center. Sequencing was done on the Pacific Biosciences RSII platform with P6-C4 chemistry and generated 185,909 reads, with an N50 length of 11,598 and containing 1,503,939,033 total bases, after filtering via SMRTpipe (v1.87). Filtered reads were corrected, trimmed, and assembled de novo with Canu (v1.7.1), using options - genomeSize $=4.0,-$ correctedErrorRate $=0.120$, -corMaxEvidenceErate $=0.15$, and -corOutCoverage $=100$, yielding five contigs (Koren et al. 2017). Three of these contigs were derived from a small number of reads ( 11 or fewer) with very low coverage relative to the largest assembled contig (less than 6x), suggesting they are most likely spuriously assembled contigs and, thus, were removed from the assembly. For the remaining two contigs, self-complementary contig ends were identified and removed with Circlator (v1.5.5), and the assembly was polished via SMRTpipe (Hunt et al. 2015). The genomic sequence was annotated with NCBI Prokaryotic Genome Annotation Pipeline (Tatusova et al. 2016).

The complete genome of Cff1037 is composed of a $3.7 \mathrm{Mb}$ circular chromosome and a putative 113-kb linear plasmid, with mean assembly coverage of $396.0 \times$. Cff1037 is predicted to encode 3,510 CDS, 47 tRNAs, three complete rRNA operons, and has a GC content of $71 \%$. These properties are similar to those of the publicly available $C$. flaccumfaciens genomes (Table 1). Analysis with fastANI revealed that Cff1037 has an average nucleotide identity (ANI) of $96.25 \%$ with the type strain, CFBP3418, consistent with Cff1037 being a strain of C. flaccumfaciens (Jain et al. 2018). Annotation with dbCAN2 predicted Cff1037 encodes 44 cazymes, seven of which contain a signal peptide (Zhang et al. 2018). Sec and Tat secretion 
Table 1. Characteristics of the genome of a strain of Curtobacterium flaccumfaciens pv. flaccumfaciens from Turkey (Cff1037) and comparison with publicly available Curtobacterium genome sequences

\begin{tabular}{|c|c|c|c|c|c|c|c|c|c|c|c|c|}
\hline Strain & $\begin{array}{l}\text { Genomic } \\
\text { feature }\end{array}$ & $\begin{array}{l}\text { Length } \\
\text { (bp) }\end{array}$ & $\begin{array}{c}\text { GC } \\
\%\end{array}$ & CDS & tRNAs & $\begin{array}{c}\text { rRNA } \\
\text { operons }\end{array}$ & $\begin{array}{l}\text { Sequencing } \\
\text { depth }\end{array}$ & Pathovar & Isolation source & $\begin{array}{c}\text { Strain ANI } \\
\text { to } \\
\text { CFBP3418 }^{a}\end{array}$ & Source & $\begin{array}{c}\text { GenBank } \\
\text { accession } \\
\text { number }\end{array}$ \\
\hline CFBP $3418^{b}$ & WGS contigs $^{c}$ & $3,827,492$ & 71.0 & 3,571 & 47 & 2 & $200 x$ & flaccumfaciens & $\begin{array}{c}\text { Phaseolus } \\
\text { vulgaris }\end{array}$ & 100.00 & GenBank & PUEZ01000000 \\
\hline \multirow[t]{5}{*}{ P990 } & & & & & & & & flaccumfaciens & Capsicum sp. & 97.41 & & \\
\hline & Chromosome & $3,736,959$ & 71.0 & 3,491 & 48 & 3 & Unknown $^{d}$ & & & $N A^{e}$ & GenBank & CP045287 \\
\hline & $\mathrm{pCff1}$ & 148,580 & 66.2 & 147 & 0 & 0 & Unknown & & & NA & GenBank & CP045288 \\
\hline & pCff2 & 25,571 & 33.6 & 22 & 0 & 0 & Unknown & & & NA & GenBank & CP045289 \\
\hline & pCff3 & 22,642 & 35.7 & 12 & 0 & 0 & Unknown & & & NA & GenBank & CP045290 \\
\hline \multirow[t]{3}{*}{ Cff1037 } & & & & & & & & flaccumfaciens & $\begin{array}{c}\text { Phaseolus } \\
\text { vulgaris }\end{array}$ & 96.25 & & \\
\hline & Chromosome & $3,667,996$ & 71.1 & 3,393 & 47 & 3 & $329.9 x$ & & & NA & This study & СР041259 \\
\hline & pCFF113 & 113,440 & 66.1 & 117 & 0 & 0 & $428.1 \times$ & & & NA & This study & CP041260 \\
\hline MEB126 & WGS contigs & $3,684,420$ & 70.9 & 3,444 & 46 & 2 & $87 x$ & $N D^{f}$ & $\begin{array}{c}\text { Arabidopsis } \\
\text { thaliana }\end{array}$ & 94.32 & GenBank & JXQU01000000 \\
\hline S5.26 & WGS contigs & $3,812,089$ & 70.7 & 3,588 & 49 & 3 & $77 x$ & ND & $\begin{array}{c}\text { Ice-wedge } \\
\text { polygon }\end{array}$ & 94.31 & GenBank & RCZL00000000 \\
\hline UCD-AKU & WGS contigs & $3,692,614$ & 70.9 & 3,386 & 47 & 3 & $261 \times$ & ND & $\begin{array}{l}\text { Residential } \\
\text { carpet }\end{array}$ & 94.21 & GenBank & APJN00000000 \\
\hline JUb65 & WGS contigs & $3,799,493$ & 71.5 & 3,549 & 47 & 2 & $395 x$ & ND & $\begin{array}{l}\text { Caenorhabditis } \\
\text { elegans }\end{array}$ & 87.13 & GenBank & SNVW00000000 \\
\hline
\end{tabular}

a ANI includes all contigs and plasmids if applicable.

b Curtobacterium flaccumfaciens pv. flaccumfaciens-type strain.

c WGS = whole genome sequence.

d Sequencing depth indicated on the associated BioSample (SAMN13022323) is unclear.

e NA = not applicable.

${ }^{f} \mathrm{ND}=$ not determined.

systems were detected with KofamKOALA annotation (Aramaki et al. 2019). Two genes encoding proteins associated with the type VII secretion system (FK523_11590 and FK523 11600) were identified by BLAST search against the UniProtKB database (Consortium 2018) and are located in a putative operon along with six other genes of unknown functions (FK523 11575-11610). In Mycobacterium tuberculosis, type VII secretion systems are required for virulence; additionally, some contribute to maintaining iron and zinc homeostasis (Chang et al. 2014). Comparatively little is known about the role of this secretion system in plant pathogenic bacteria, although deletion of a locus containing type VII secretion system homologs in Streptomyces scabies did not affect virulence (Chang et al. 2014; Fyans et al. 2013).

The putative linear plasmid, pCFF113, has high nucleotide identity (99.7 to $100 \%)$ to two contigs from the draft assembly of the $C$. flaccumfaciens pv. flaccumfaciens-type strain CFBP 3418 (GenBank accession numbers PUEZ01000006.1 and PUEZ01000008.1), and to pCff1 from C. flaccumfaciens pv. flaccumfaciens strain P990. Plasmids pCFF113 and pCff1 are colinear, though pCff1 contains additional 5.5 and $29.6 \mathrm{~kb}$ sequences at the $5^{\prime}$ and $3^{\prime}$ ends, respectively. Read mapping analysis with minimap2 (v2.17) does not support a circular structure for pCFF113 (Li 2018), nor does pCFF113 contain self-complementary ends, consistent with the failure of Circlator to circularize this plasmid. These results suggest that this plasmid is not unique to $\mathrm{Cff} 1037$, but that genetic diversity in the sequence and even structure of this plasmid may exist among $C$. flaccumfaciens pv. flaccumfaciens strains. pCFF113 is not present in the four other $C$. flaccumfaciens draft genomes, consistent with a role in plant pathogenicity, although an $\sim 5.6 \mathrm{~kb}$ region of pCFF113 that includes genes involved in carbohydrate metabolism (FK523_17505-17525) was detected in all C. flaccumfaciens genomes, except JUb65. A linear plasmid, pCSL1, occurs in Clavibacter sepedonicus strain ATCC33113 (GenBank accession number AM849036.1), a Gram-positive coryneform bacterial plant pathogen related to Curtobacterium (Bentley et al. 2008). Comparison of the complete sequences of pCFF113 and pCSL1 with PROmer (v3.07) revealed eight conserved regions ranging from 1.1 to $4.3 \mathrm{~kb}$ (totaling $18.4 \mathrm{~kb}$ ) with 55 to $70 \%$ translated amino acid identity (Kurtz et al. 2004). This suggests that pCFF113 is distantly related to pCSL1.

Clavibacter michiganensis strain NCPPB382 (GenBank accession number AM711866) encodes many serine proteases, including pat-1, which is required for virulence (Bentley et al. 2008; Burger et al. 2005; Thapa et al. 2017). Clavibacter sepedonicus strain ATCC33113 also encodes numerous serine proteases, including one on PCSL1, and these genes are often associated with mobile elements (Bentley et al. 2008). Cff1037 is predicted to encode at least 
five serine proteases, four of which are located on PCFF113. Three of the pCFF113-encoded serine proteases (FK523_17305, FK523_17310, and FK523_17320) are clustered together and are associated with an IS481 family-transposase, whereas the fourth (FK523_17500) is located $\sim 35 \mathrm{~kb}$ away and is associated with an IS3 family-transposase and a gene encoding a tra-like protein. BLASTp comparisons indicate that these $C$. flaccumfaciens pv. flaccumfaciens serine proteases have between 30 to $40 \%$ amino acid identity with the Clavibacter michiganensis serine protease pat-1, indicating that they are related but may not be orthologous. Together, these results further support a role for pCFF113 in pathogenicity and an evolutionary history of horizontal gene transfer.

Data availability. The complete genome sequence for $\mathrm{Cff} 1037$ has been deposited into GenBank under the accession numbers CP041259 and CP041260 (BioProject PRJNA551505; BioSample SAMN12153678). Raw reads have been deposited into Sequencing Read Archive in association with BioProject PRJNA551505.

\section{Acknowledgments}

We thank Erkan Konuk for coordinating the surveys of common bean fields in Turkey. We also thank the UC Davis DNA Technologies \& Expression Analysis Core Laboratory, supported by NIH Shared Instrumentation Grant 1S10OD010786-01, and Oanh Ngyuen for technical assistance.

\section{Literature Cited}

Agarkova, I. V., Lambrecht, P. A., Vidaver, A. K., and Harveson, R. M. 2012. Genetic diversity among Curtobacterium flaccumfaciens pv. flaccumfaciens populations in the American High Plains. Can. J. Microbiol. 58:788-801.

Aramaki, T., Blanc-Mathieu, R., Endo, H., Ohkubo, K., Kanehisa, M., Goto, S., and Ogata, H. 2019. KofamKOALA: KEGG ortholog assignment based on profile HMM and adaptive score threshold. Bioinformatics 36:2251-2252.

Bentley, S. D., Corton, C., Brown, S. E., Barron, A., Clark, L., Doggett, J., Harris, B., Ormond, D., Quail, M. A., May, G., Francis, D., Knudson, D., Parkhill, J., and Ishimaru, C. A. 2008. Genome of the actinomycete plant pathogen Clavibacter michiganensis subsp. sepedonicus suggests recent niche adaptation. J. Bacteriol. 190:2150-2160.

Burger, A., Gräfen, I., Engemann, J., Niermann, E., Pieper, M., Kirchner, O., Gartemann, K.-H., and Eichenlaub, R. 2005. Identification of homologues to the pathogenicity factor Pat-1, a putative serine protease of Clavibacter michiganensis subsp. michiganensis. Microbiol. Res. 160:417-427.

Chang, J. H., Desveaux, D., and Creason, A. L. 2014. The ABCs and 123s of bacterial secretion systems in plant pathogenesis. Annu. Rev. Phytopathol. 52: 317-345.

Claflin, L. E., Vidaver, A. K., and Sasser, M. 1987. MXP, a semi-selective medium for Xanthomonas campestris pv. phaseoli. Phytopathology 77:730-734.

Consortium, T. U. 2018. UniProt: A worldwide hub of protein knowledge. Nucleic Acids Res. 47:D506-D515.

EPPO. 2011. Curtobacterium flaccumfaciens pv. flaccumfaciens. EPPO Bull. 41: 320-328.

Fyans, J. K., Bignell, D., Loria, R., Toth, I., and Palmer, T. 2013. The ESX/type VII secretion system modulates development, but not virulence, of the plant pathogen Streptomyces scabies. Mol. Plant Pathol. 14:119-130.

Gonçalves, R. M., Balbi-Peña, M. I., Soman, J. M., Maringoni, A. C., Taghouti, G., Fischer-Le Saux, M., and Portier, P. 2019. Genetic diversity of Curtobacterium flaccumfaciens revealed by multilocus sequence analysis. Eur. J. Plant Pathol. 154: 189-202.

Harveson, R. M., Schwartz, H. F., Urrea, C. A., and Yonts, C. D. 2015. Bacterial wilt of dry-edible beans in the Central High Plains of the U.S.: Past, present, and future. Plant Dis. 99:1665-1677.

Harveson, R. M., Schwartz, H. F., Vidaver, A. K., Lambrecht, P. A., and Otto, K. L. 2006. New outbreaks of bacterial wilt of dry bean in Nebraska observed from field infections. Plant Dis. 90:681.

Hedges, F. 1922. A bacterial wilt of the bean caused by Bacterium flaccumfaciens nov. sp. Science 55:433-434.

Hunt, M., Silva, N. D., Otto, T. D., Parkhill, J., Keane, J. A., and Harris, S. R. 2015. Circlator: Automated circularization of genome assemblies using long sequencing reads. Genome Biol. 16:294.
Jain, C., Rodriguez-R, L. M., Phillippy, A. M., Konstantinidis, K. T., and Aluru, S. 2018. High throughput ANI analysis of $90 \mathrm{~K}$ prokaryotic genomes reveals clear species boundaries. Nat. Commun. 9:5114.

Jensen, M. A., Webster, J. A., and Straus, N. 1993. Rapid identification of bacteria on the basis of polymerase chain reaction-amplified ribosomal DNA spacer polymorphisms. Appl. Environ. Microbiol. 59:945-952.

Kado, C. I., and Heskett, M. G. 1970. Selective media for isolation of Agrobacterium, Corynebacterium, Enwinia, Pseudomonas, and Xanthomonas. Phytopathology 60:969-976.

Koike, S. T., Barak, J. D., Henderson, D. M., and Gilbertson, R. L. 1999. Bacterial blight of leek: A new disease in California caused by Pseudomonas syringae. Plant Dis. 83:165-170.

Koren, S., Walenz, B. P., Berlin, K., Miller, J. R., Bergman, N. H., and Phillippy, A. M. 2017. Canu: Scalable and accurate long-read assembly via adaptive k-mer weighting and repeat separation. Genome Res. 27:722-736.

Kurtz, S., Phillippy, A., Delcher, A. L., Smoot, M., Shumway, M., Antonescu, C., and Salzberg, S. L. 2004. Versatile and open software for comparing large genomes. Genome Biol. 5:R12.

Li, H. 2018. Minimap2: Pairwise alignment for nucleotide sequences. Bioinformatics 34: 3094-3100.

Osdaghi, E., Taghavi, S. M., Fazliarab, A., Elahifard, E., and Lamichhane, J. R. 2015. Characterization, geographic distribution and host range of Curtobacterium flaccumfaciens: An emerging bacterial pathogen in Iran. Crop Prot. 78:185-192.

Soares, R. M., Fantinato, G. G. P., Darben, L. M., Marcelino-Guimarães, F. C., Seixas, C. D. S., and Carneiro, G. E. S. 2013. First report of Curtobacterium flaccumfaciens pv. flaccumfaciens on soybean in Brazil. Trop. Plant Pathol. 38:452-454.

Suslow, T. V., Schroth, M. N., and Isaka, M. 1982. Application of a rapid method for Gram differentiation of plant pathogenic and saprophytic bacteria without staining. Phytopathology 72:917-918.

Tatusova, T., DiCuccio, M., Badretdin, A., Chetvernin, V., Nawrocki, E. P., Zaslavsky, L., Lomsadze, A., Pruitt, K. D., Borodovsky, M., and Ostell, J. 2016. NCBI prokaryotic genome annotation pipeline. Nucleic Acids Res. 44:6614-6624.

Tegli, S., Sereni, A., and Surico, G. 2002. PCR-based assay for the detection of Curtobacterium flaccumfaciens pv. flaccumfaciens in bean seeds. Lett. Appl. Microbiol. 35:331-337.

Thapa, S. P., Pattathil, S., Hahn, M. G., Jacques, M. A., Gilbertson, R. L., and Coaker, G. 2017. Genomic analysis of Clavibacter michiganensis reveals insight into virulence strategies and genetic diversity of a Gram-positive bacterial pathogen. Mol. PlantMicrobe Interact. 30:786-802.

Zaumeyer, W. J., and Thomas, H. R. 1957. Page 255 in: A Monographic Study of Bean Diseases and Methods for Their Control. United States Department of Agriculture, Economic Research Service. Tech. Bull. 169625.

Zhang, H., Yohe, T., Huang, L., Entwistle, S., Wu, P., Yang, Z., Busk, P. K., Xu, Y., and Yin, Y. 2018. dbCAN2: A meta server for automated carbohydrate-active enzyme annotation. Nucleic Acids Res. 46:W95-W101. 